\title{
Best proximity point results for generalized contractions in metric spaces
}

\author{
Alireza Amini-Harandi ${ }^{1}$, Nawab Hussain ${ }^{2}$ and Farhana Akbar ${ }^{3 *}$ \\ Dedicated to Professor Wataru Takahashi on the occasion of his seventieth birthday
}

"Correspondence:

ridaf75@yahoo.com

${ }^{3}$ Department of Mathematics,

GDCW, Bosan Road, Multan,

Pakistan

Full list of author information is

available at the end of the article

\begin{abstract}
In this paper, we first introduce a cyclic generalized contraction map in metric spaces and give an existence result for a best proximity point of such mappings in the setting of a uniformly convex Banach space. Then we give an existence and uniqueness best proximity point theorem for non-self proximal generalized contractions. Moreover, an algorithm is exhibited to determine such a unique best proximity point. Some examples are also given to support our main results. Our results extend and improve certain recent results in the literature.
\end{abstract}

MSC: 46N40; 47H10; 54H25; 46T99

Keywords: optimal solution; best proximity point; cyclic generalized contraction map; proximal generalized contraction; metric space; uniformly convex Banach space

\section{Introduction and preliminaries}

Fixed point theory is indispensable for solving various equations of the form $T x=x$ for self-mappings $T$ defined on subsets of metric spaces. Given nonempty subsets $A$ and $B$ of a metric space and a non-self mapping $T: A \rightarrow B$, the equation $T x=x$ does not necessarily have a solution, which is known as a fixed point of the mapping $T$. However, in such circumstances, it may be speculated to determine an element $x$ for which the error $d(x, T x)$ is minimum, in which case $x$ and $T x$ are in close proximity to each other. Best approximation theorems and best proximity point theorems are relevant in this perspective. One of the most interesting results in this direction is due to Fan [1] and can be stated as follows.

Theorem $\mathbf{F}$ Let $K$ be a nonempty compact convex subset of a normed space $E$ and let $T: K \rightarrow E$ be a continuous non-self-mapping. Then there exists an $x$ such that $\|x-T x\|=$ $d(K, T x)=\inf \{\|T x-u\|: u \in K\}$.

Many generalizations and extensions of this theorem appeared in the literature (see [26] and references therein).

On the other hand, though best approximation theorems ensure the existence of approximation solutions, such results need not yield optimal solutions. But, best proximity point theorems provide sufficient conditions that assure the existence of approximate solutions which are optimal as well. A best proximity point theorem furnishes sufficient conditions that ascertain the existence of an optimal solution to the problem of globally minimizing the error $d(x, T x)$, and hence the existence of a consummate approximate solution to the

(c) 2013 Amini-Harandi et al.: licensee Springer. This is an Open Access article distributed under the terms of the Creative Commons Attribution License (http://creativecommons.org/licenses/by/2.0), which permits unrestricted use, distribution, and reproduction in any medium, provided the original work is properly cited. 
equation $T x=x$. Indeed, in view of the fact that $d(x, T x) \geq d(A, B)$ for all $x$, a best proximity point theorem offers sufficient conditions for the existence of an element $x$, called a best proximity point of the mapping $T$, satisfying the condition that $d(x, T x)=d(A, B)$. Further, it is interesting to observe that best proximity point theorems also emerge as a natural generalization of fixed point theorems for a best proximity point reduces to a fixed point if the mapping under consideration is a self-mapping. Best proximity point theory of cyclic contraction maps has been studied by many authors; see [7-15] and references therein. Investigation of several variants of contractions for the existence of a best proximity point can be found in [16-19]. Best proximity point theorems for multivalued mappings are available in $[20,21]$.

\section{Best proximity points for cyclic generalized contractions}

Let $A$ and $B$ be nonempty subsets of a metric space $(X, d), T: A \cup B \rightarrow A \cup B, T(A) \subseteq B$ and $T(B) \subseteq A$. We say that

(a) $T$ is cyclic contraction $[10]$ if

$$
d(T x, T y) \leq k d(x, y)+(1-k) d(A, B) \quad \text { for all } x \in A, y \in B
$$

for some $k \in[0,1)$, where

$$
d(A, B)=\inf \{d(x, y): x \in A, y \in B\} .
$$

(b) $x \in A \cup B$ is a best proximity point for $T$ if $d(x, T x)=d(A, B)$.

We first introduce the following new class of cyclic generalized contraction maps.

Definition 2.1 Let $A$ and $B$ be nonempty subsets of a metric space $(X, d)$. A map $T: A \cup$ $B \rightarrow A \cup B$ is a cyclic generalized contraction map if $T(A) \subseteq B, T(B) \subseteq A$ and

$$
d(T x, T y) \leq \alpha(d(x, y)) d(x, y)+(1-\alpha(d(x, y))) d(A, B)
$$

for each $x \in A$ and $y \in B$, where $\alpha:[d(A, B), \infty) \rightarrow[0,1)$ satisfies $\lim \sup _{s \rightarrow t^{+}} \alpha(s)<1$ for each $t \in(d(A, B), \infty)$.

If $\alpha(t)=k$ for each $t \in[d(A, B), \infty)$, where $k \in[0,1)$ is constant, then $T$ is a cyclic contraction.

A Banach space $X$ is said to be uniformly convex if there exists a strictly increasing function $\delta:(0,2] \rightarrow[0,1]$ such that the following implication holds for all $x_{1}, x_{2}, p \in X, R>0$ and $r \in[0,2 R]$ :

$$
\left\|x_{i}-p\right\| \leq R, \quad i=1,2 \quad \text { and } \quad\left\|x_{1}-x_{2}\right\| \geq r \quad \Rightarrow \quad\left\|\frac{x_{1}+x_{2}}{2}-p\right\| \leq\left(1-\delta\left(\frac{r}{R}\right)\right) R .
$$

Theorem 2.1 (Geraghty [22]) Let $(X, d)$ be a complete metric space and let $T: X \rightarrow X$ be a map satisfying

$$
d(T x, T y) \leq \alpha(d(x, y)) d(x, y) \quad \text { for each } x, y \in X,
$$


where $\alpha:[0, \infty) \rightarrow[0,1)$ satisfies $\lim \sup _{s \rightarrow t^{+}} \alpha(s)<1$ for each $t \in(0, \infty)$. Then $T$ has a fixed point.

Now, we are ready to state our main result in this section.

Theorem 2.2 Let $A$ and $B$ be nonempty closed and convex subsets of a uniformly convex Banach space $X$ and let $T: A \cup B \rightarrow A \cup B$ be a cyclic generalized contraction map. Then $T$ has a best proximity point.

Proof Suppose that $d(A, B)=0$, then the theorem follows from the above mentioned Geraghty fixed point theorem. Therefore, we may assume that $d(A, B)>0$. Let $x_{0} \in A$ and let $x_{n+1}=T x_{n}$ for each $n \in \mathbb{N}$. Then from (2.1) we have

$$
\begin{aligned}
& \left\|x_{2 m+1}-x_{2 n}\right\| \\
& \quad \leq \alpha\left(\left\|x_{2 m}-x_{2 n-1}\right\|\right)\left\|x_{2 m}-x_{2 n-1}\right\|+\left(1-\alpha\left(\left\|x_{2 m}-x_{2 n-1}\right\|\right)\right) d(A, B)
\end{aligned}
$$

for each $m, n \in \mathbb{N}$. Since $\alpha\left(\left\|x_{2 m}-x_{2 n-1}\right\|\right)<1$ and $\left\|x_{2 m}-x_{2 n-1}\right\| \geq d(A, B)$, so we have

$$
\begin{aligned}
& \alpha\left(\left\|x_{2 m}-x_{2 n-1}\right\|\right)\left\|x_{2 m}-x_{2 n-1}\right\|+\left(1-\alpha\left(\left\|x_{2 m}-x_{2 n-1}\right\|\right)\right) d(A, B) \\
& \quad \leq\left\|x_{2 m}-x_{2 n-1}\right\| .
\end{aligned}
$$

From (2.2) and (2.3), we get

$$
\left\|x_{2 m+1}-x_{2 n}\right\| \leq\left\|x_{2 m}-x_{2 n-1}\right\|
$$

for each $m, n \in \mathbb{N}$. Then from (2.4) we get $\left\|x_{n}-x_{n+1}\right\| \leq\left\|x_{n-1}-x_{n}\right\|$ for each $n \in \mathbb{N}$, and so $\left\{\left\|x_{n}-x_{n+1}\right\|\right\}$ is a nonnegative nonincreasing sequence in $\mathbb{R}$. Hence $\left\{\left\|x_{n}-x_{n+1}\right\|\right\}$ converges to some real number $r_{0} \geq d(A, B)$. On the contrary, assume that $r_{0}>d(A, B)$. Since $\lim \sup _{s \rightarrow r_{0}^{+}} \alpha(s)<1$ and $\alpha\left(r_{0}\right)<1$, there exist $r \in(0,1)$ and $\epsilon>0$ such that $\alpha(s) \leq r$ for all $s \in\left[r_{0}, r_{0}+\epsilon\right]$. We can take $N_{0} \in \mathbb{N}$ such that $r_{0} \leq\left\|x_{n}-x_{n+1}\right\| \leq r_{0}+\epsilon$ for all $n \geq N_{0}$. Then

$$
\alpha\left(\left\|x_{n}-x_{n+1}\right\|\right) \leq r \quad \text { for } n \geq N_{0}
$$

Let $m \in\{n, n-1\}$ and let $n \geq N_{0}$. Then from (2.2) and the above inequality, we get (note that $\left.\left\|x_{2 m}-x_{2 n-1}\right\|-d(A, B) \geq 0\right)$

$$
\begin{aligned}
\left\|x_{2 m+1}-x_{2 n}\right\| & \leq \alpha\left(\left\|x_{2 m}-x_{2 n-1}\right\|\right)\left(\left\|x_{2 m}-x_{2 n-1}\right\|-d(A, B)\right)+d(A, B) \\
& \leq r\left(\left\|x_{2 m}-x_{2 n-1}\right\|-d(A, B)\right)+d(A, B)=r\left\|x_{2 m}-x_{2 n-1}\right\|+(1-r) d(A, B)
\end{aligned}
$$

for each $n \geq N_{0}$ and $m \in\{n, n-1\}$. So, we get

$$
\left\|x_{n}-x_{n+1}\right\| \leq r\left\|x_{n-1}-x_{n}\right\|+(1-r) d(A, B) \quad \text { for } n \geq 2 N_{0} .
$$

Letting $n \rightarrow \infty$, (2.5) implies $r_{0}=\lim _{n \rightarrow \infty}\left\|x_{n}-x_{n+1}\right\| \leq d(A, B)$, a contradiction. Then

$$
\lim _{n \rightarrow \infty}\left\|x_{n}-x_{n+1}\right\|=d(A, B) .
$$


Now, we show that

$$
\lim _{n \rightarrow \infty}\left\|x_{2 n+2}-x_{2 n}\right\|=0
$$

and

$$
\lim _{n \rightarrow \infty}\left\|x_{2 n+3}-x_{2 n+1}\right\|=0
$$

To show that $\lim _{n \rightarrow \infty}\left\|x_{2 n+2}-x_{2 n}\right\|=0$, on the contrary, assume that there exists $\epsilon_{0}>0$ such that for each $k \in \mathbb{N}$ there exists $n_{k}>k$ such that

$$
\left\|x_{2 n_{k}+2}-x_{2 n_{k}}\right\| \geq \epsilon_{0} .
$$

Choose $0<\gamma<1$ such that $\frac{\epsilon_{0}}{\gamma}>d(A, B)$ and choose $\epsilon$ such that

$$
0<\epsilon<\min \left\{\frac{\epsilon_{0}}{\gamma}-d(A, B), \frac{d(A, B) \delta(\gamma)}{1-\delta(\gamma)}\right\} \text {. }
$$

By (2.6) there exists $N_{1}$ such that

$$
\left\|x_{2 n_{k}+2}-x_{2 n_{k}+1}\right\| \leq d(A, B)+\epsilon \quad \text { for all } n_{k} \geq N_{1} \text {. }
$$

Also, there exists $N_{2}$ such that

$$
\left\|x_{2 n_{k}}-x_{2 n_{k}+1}\right\| \leq d(A, B)+\epsilon \text { for all } n_{k} \geq N_{2}
$$

Let $N=\max \left\{N_{1}, N_{2}\right\}$. It follows from (2.9)-(2.11) and the uniform convexity of $X$ that

$$
\left\|\frac{x_{2 n_{k}+2}+x_{2 n_{k}}}{2}-x_{2 n_{k}+1}\right\| \leq\left(1-\delta\left(\frac{\epsilon_{0}}{d(A, B)+\epsilon}\right)\right)(d(A, B)+\epsilon)
$$

for all $n_{k} \geq N$. As $\frac{x_{2 n_{k}+2+x} n_{k}}{2} \in A$, the choice of $\epsilon$ and the fact that $\delta$ is strictly increasing imply that

$$
\left\|\frac{x_{2 n_{k}+2}+x_{2 n_{k}}}{2}-x_{2 n_{k}+1}\right\|<d(A, B) \quad \text { for all } n_{k} \geq N
$$

a contradiction. A similar argument shows $\left\|x_{2 n+3}-x_{2 n+1}\right\| \rightarrow 0$ as $n \rightarrow \infty$. Hence, (2.7) and (2.8) hold.

Now we show that for each $\epsilon>0$, there exists $N \in \mathbb{N}$ such that for all $m>n \geq N$,

$$
\left\|x_{2 m}-x_{2 n+1}\right\|<d(A, B)+\epsilon .
$$

On the contrary, assume that there exists $\epsilon_{1}>0$ such that for each $k \geq 1$ there is $m_{k}>n_{k} \geq k$ satisfying

$$
\left\|x_{2 m_{k}}-x_{2 n_{k}+1}\right\| \geq d(A, B)+\epsilon_{1}
$$


and

$$
\left\|x_{2\left(m_{k}-1\right)}-x_{2 n_{k}+1}\right\|<d(A, B)+\epsilon_{1} .
$$

It follows from (2.13), (2.14) and the triangle inequality that

$$
\begin{aligned}
d(A, B)+\epsilon_{1} & \leq\left\|x_{2 m_{k}}-x_{2 n_{k}+1}\right\| \\
& \leq\left\|x_{2 m_{k}}-x_{2\left(m_{k}-1\right)}\right\|+\left\|x_{2\left(m_{k}-1\right)}-x_{2 n_{k}+1}\right\| \\
& <\left\|x_{2 m_{k}}-x_{2\left(m_{k}-1\right)}\right\|+d(A, B)+\epsilon_{1} .
\end{aligned}
$$

Letting $k \rightarrow \infty$, (2.7) implies

$$
\lim _{k \rightarrow \infty}\left\|x_{2 m_{k}}-x_{2 n_{k}+1}\right\|=d(A, B)+\epsilon_{1} .
$$

Let $t_{0}=d(A, B)+\epsilon_{1}$. Since $\lim \sup _{s \rightarrow t_{0}^{+}} \alpha(s)<1$ and $\alpha\left(t_{0}\right)<1$, there exist $r^{\prime} \in(0,1)$ and $\epsilon^{\prime}>0$ such that $\alpha(s) \leq r^{\prime}$ for all $s \in\left[t_{0}, t_{0}+\epsilon^{\prime}\right]$. Thanks to (2.15), we can take $K_{0} \in \mathbb{N}$ such that $t_{0} \leq\left\|x_{2 m_{k}}-x_{2 n_{k}+1}\right\| \leq t_{0}+\epsilon^{\prime}$ for all $k \geq K_{0}$. Then

$$
\alpha\left(\left\|x_{2 m_{k}}-x_{2 n_{k}+1}\right\|\right) \leq r^{\prime} \quad \text { for } k \geq K_{0}
$$

and so from (2.2) we get

$$
\left\|x_{2 m_{k}+1}-x_{2 n_{k}+2}\right\| \leq r^{\prime}\left\|x_{2 m_{k}}-x_{2 n_{k}+1}\right\|+\left(1-r^{\prime}\right) d(A, B) \quad \text { for } k \geq K_{0} \text {. }
$$

From (2.4) and (2.16), we get

$$
\begin{aligned}
\left\|x_{2 m_{k}}-x_{2 n_{k}+1}\right\| \leq & \left\|x_{2 m_{k}}-x_{2 m_{k}+2}\right\|+\left\|x_{2 m_{k}+2}-x_{2 n_{k}+3}\right\|+\left\|x_{2 n_{k}+3}-x_{2 n_{k}+1}\right\| \\
\leq & \left\|x_{2 m_{k}}-x_{2 m_{k}+2}\right\|+\left\|x_{2 m_{k}+1}-x_{2 n_{k}+2}\right\|+\left\|x_{2 n_{k}+3}-x_{2 n_{k}+1}\right\| \\
\leq & \left\|x_{2 m_{k}}-x_{2 m_{k}+2}\right\|+\left\|x_{2 n_{k}+3}-x_{2 n_{k}+1}\right\| \\
& \quad+r^{\prime}\left\|x_{2 m_{k}}-x_{2 n_{k}+1}\right\|+\left(1-r^{\prime}\right) d(A, B)
\end{aligned}
$$

for each $k \geq K_{0}$. Letting $k \rightarrow \infty$ and using (2.7), (2.8), (2.15) and (2.17), we get

$$
d(A, B)+\epsilon_{1} \leq r^{\prime}\left(d(A, B)+\epsilon_{1}\right)+\left(1-r^{\prime}\right) d(A, B)=d(A, B)+r^{\prime} \epsilon_{1},
$$

a contradiction. Thus (2.12) holds.

Now we show that $\left\{x_{2 n}\right\}$ is a Cauchy sequence in $A$. To show the claim, we assume the contrary. Then there exists $\epsilon_{2}>0$ such that for each $k \geq 1$, there exist $p_{k}>q_{k} \geq k$ such that

$$
\left\|x_{2 p_{k}}-x_{2 q_{k}}\right\| \geq \epsilon_{2} .
$$

Choose $0<\gamma<1$ such that $\frac{\epsilon_{2}}{\gamma}>d(A, B)$ and choose $\epsilon>0$ such that

$$
\epsilon<\min \left\{\frac{\epsilon_{2}}{\gamma}-d(A, B), \frac{d(A, B) \delta(\gamma)}{1-\delta(\gamma)}\right\}
$$


By (2.6) there exists $N_{1}$ such that

$$
\left\|x_{2 n_{k}}-x_{2 n_{k}+1}\right\|<d(A, B)+\epsilon \quad \text { for all } n_{k} \geq N_{1} \text {. }
$$

By (2.12) there exists $N_{2}$ such that

$$
\left\|x_{2 m_{k}}-x_{2 n_{k}+1}\right\|<d(A, B)+\epsilon \text { for all } m_{k}>n_{k} \geq N_{2} \text {. }
$$

Let $N=\max \left\{N_{1}, N_{2}\right\}$. It follows from (2.18)-(2.20) and the uniform convexity of $X$ that

$$
\left\|\frac{x_{2 m_{k}}+x_{2 n_{k}}}{2}-x_{2 n_{k}+1}\right\| \leq\left(1-\delta\left(\frac{\epsilon_{2}}{d(A, B)+\epsilon}\right)\right)(d(A, B)+\epsilon) \quad \text { for all } m_{k}>n_{k} \geq N
$$

By the choice of $\epsilon$ and the fact that $\delta$ is strictly increasing, we have

$$
\left\|\frac{x_{2 m_{k}}+x_{2 n_{k}}}{2}-x_{2 n_{k}+1}\right\|<d(A, B) \quad \text { for all } m_{k}>n_{k} \geq N
$$

a contradiction. Thus $\left\{x_{2 n}\right\}$ is a Cauchy sequence in $A$. Now the completeness of $X$ and the closedness of $A$ imply that

$$
\lim _{n \rightarrow \infty} x_{2 n}=x \in A
$$

Since (note that $x \in A$ and $x_{2 n-1} \in B$ )

$$
d(A, B) \leq\left\|x-x_{2 n-1}\right\| \leq\left\|x-x_{2 n}\right\|+\left\|x_{2 n}-x_{2 n-1}\right\| \quad \text { for each } n \in \mathbb{N},
$$

it follows from (2.6) and (2.21) that

$$
\lim _{n \rightarrow \infty}\left\|x-x_{2 n-1}\right\|=d(A, B) .
$$

Since

$$
\begin{aligned}
d(A, B) & \leq\left\|x_{2 n}-T x\right\|=\left\|T x_{2 n-1}-T x\right\| \\
& \leq \alpha\left(\left\|x_{2 n-1}-x\right\|\right)\left\|x_{2 n-1}-x\right\|+\left(1-\alpha\left(\left\|x_{2 n-1}-x\right\|\right)\right) d(A, B) \\
& \leq\left\|x_{2 n-1}-x\right\|
\end{aligned}
$$

for each $n \in \mathbb{N}$, then from (2.21)-(2.23) we get $\|x-T x\|=d(A, B)$. Therefore, $T$ has a best proximity point.

Now we illustrate our main result by the following example.

Example 2.1 Consider the uniformly convex Banach space $X=\mathbb{R}^{2}$ with Euclidean metric. Let $A:=\{(0, x): 0 \leq x\}$ and $B:=\{(2, y): 0 \leq y\}$. Then $A$ and $B$ are nonempty closed and convex subsets of $X$ and $d(A, B)=2$.

Let $T: A \cup B \rightarrow A \cup B$ be defined as

$$
T(0, x)=\left(2, \frac{x}{2}\right) \quad \text { and } \quad T(2, y)=\left(0, \frac{y}{2}\right) \quad \text { for each } x, y \geq 0 .
$$


We show that $T$ is a generalized cyclic contraction map with $\alpha(t)=\frac{1}{2}$ for $t \in[2, \infty)$. To show the claim, notice first that the function $f(t)=\sqrt{4+t^{2}}-2, t \in[0, \infty)$ is convex, $f(0)=$ 0 and so $f\left(\frac{t}{2}\right) \leq \frac{1}{2} f(t)$ for $t \in[0, \infty)$. For each $x, y \in[0, \infty)$, we have

$$
\begin{aligned}
d(T(0, x), T(2, y)) & =\sqrt{4+\left(\frac{|x-y|}{2}\right)^{2}} \\
& \leq 2+\frac{1}{2}\left(\sqrt{4+(|x-y|)^{2}}-2\right) \\
& =\frac{1}{2}\left(\sqrt{4+(|x-y|)^{2}}\right)+\frac{1}{2} 2 \\
& =\frac{1}{2} d((0, x),(2, y))+\frac{1}{2} d(A, B) .
\end{aligned}
$$

Thus all of the hypotheses of Theorem 2.2 are satisfied and then $T$ has a best proximity point $((0,0)$ is a best proximity point of $T$ in $A)$.

Now we provide the following example to show that Theorem 2.2 is an essential extension of Theorem 3.10 of Eldred and Veeramani [10].

Example 2.2 Consider the uniformly convex Banach space $X=\mathbb{R}^{2}$ with Euclidean metric. Let $A:=\{(0, x): 0 \leq x\}$ and $B:=\{(2, y): 0 \leq y\}$. Then $A$ and $B$ are nonempty closed and convex subsets of $X$ and $d(A, B)=2$.

Let $T: A \cup B \rightarrow A \cup B$ be defined as

$$
T(0, x)=(2, \ln (1+x)) \quad \text { and } \quad T(2, y)=(0, \ln (1+y)) \quad \text { for each } x, y \geq 0 .
$$

We first show that $T$ is not a cyclic contraction map. To show the claim, on the contrary, assume that there exists $k \in[0,1)$ such that

$$
d(T(0, x), T(2, y)) \leq k d((0, x),(2, y))+(1-k) d(A, B)
$$

for each $x, y \in[0, \infty)$. Then

$$
\sqrt{4+(\ln (1+x)-\ln (1+y))^{2}} \leq k \sqrt{4+(x-y)^{2}}+2(1-k)
$$

for each $x, y \in[0, \infty)$. Letting $y=0$, we get

$$
\frac{\sqrt{4+(\ln (1+x))^{2}}-2}{\sqrt{4+x^{2}}-2} \leq k
$$

for each $x \in(0, \infty)$. Then

$$
1=\lim _{x \rightarrow 0^{+}} \frac{\sqrt{4+(\ln (1+x))^{2}}-2}{\sqrt{4+x^{2}}-2} \leq k,
$$

a contradiction. Now, we show that $T$ is a cyclic generalized contraction, where $\alpha(t)=$ $\frac{\sqrt{4+\left(\ln \left(1+\sqrt{t^{2}-4}\right)\right)^{2}}-2}{t-2}$ for $t \in(2, \infty)$. Notice first that the function $f(t)=\ln (1+t):[0, \infty) \rightarrow$ 
$[0, \infty)$ is increasing and concave and so is subadditive, that is, $f(r+s) \leq f(r)+f(s)$ for each $r, s \in[0, \infty)$. For each $x, y \in[0, \infty)$ with $x \neq y$, we have (note that for $x=y$ we have $d(T(0, x), T(2, y))=d((0, x),(2, y))=2=d(A, B)$ and so $(2.1)$ trivially holds for $\alpha(2)=0)$

$$
\begin{aligned}
& \begin{aligned}
d(T(0, x), T(2, y)) & =\sqrt{4+(\ln (1+x)-\ln (1+y))^{2}} \\
& \leq \sqrt{4+(\ln (1+|x-y|))^{2}} \\
& =\frac{\sqrt{4+(\ln (1+|x-y|))^{2}}-2}{\sqrt{4+(x-y)^{2}}-2}\left(\sqrt{4+(x-y)^{2}}-2\right)+2,
\end{aligned} \\
& \alpha\left(\sqrt{4+(x-y)^{2}}\right)\left(\sqrt{4+(x-y)^{2}}-2\right)+2 \\
& \quad=\alpha(d((0, x),(2, y))) d((0, x),(2, y))+2(1-\alpha(d((0, x),(2, y)))) .
\end{aligned}
$$

Thus all of the hypotheses of Theorem 2.2 are satisfied and then $T$ has a best proximity point $((0,0)$ is a best proximity point of $T$ in $A)$. But since $T$ is not a cyclic contraction, we cannot invoke the main result of [10] to show the existence of the best proximity point for $T$.

\section{Best proximity points for generalized contraction}

Given nonempty subsets $A$ and $B$ of a metric space, we recall the following notations and notions, which will be used in the sequel.

$$
\begin{aligned}
& d(A, B)=\inf \{d(x, y): x \in A \text { and } y \in B\}, \\
& A_{0}=\{x \in A: d(x, y)=d(A, B) \text { for some } y \in B\}, \\
& B_{0}=\{y \in B: d(x, y)=d(A, B) \text { for some } x \in A\} .
\end{aligned}
$$

The set $B$ is said to be approximatively compact with respect to $A$ if every sequence $\left\{y_{n}\right\}$ in $B$, satisfying the condition that $d\left(x, y_{n}\right) \rightarrow d(x, B)$ for some $x$ in $A$, has a convergent subsequence. It is trivial to note that every set is approximatively compact with respect to itself, and that every compact set $B$ is approximatively compact with respect to $A$.

A mapping $T: A \rightarrow B$ is said to be a proximal contraction if there exists a non-negative number $\alpha<1$ such that for all $u_{1}, u_{2}, x_{1}, x_{2}$ in $A$,

$$
d\left(u_{1}, T x_{1}\right)=d(A, B)=d\left(u_{2}, T x_{2}\right) \quad \Rightarrow \quad d\left(u_{1}, u_{2}\right) \leq \alpha d\left(x_{1}, x_{2}\right) .
$$

To establish our results, we introduce the following new class of proximal contractions.

Definition 3.1 Let $T: A \rightarrow B, g: A \rightarrow A$ be two maps. Let $\varphi:[0, \infty) \rightarrow[0, \infty)$ satisfy

$$
\varphi(0)=0, \quad \varphi(t)<t, \quad \text { and } \quad \limsup _{s \rightarrow t^{+}} \varphi(s)<t \quad \text { for each } t>0 .
$$

Then $T$ is said to be a $(\varphi, g)$-proximal contraction if

$$
d\left(u_{1}, T x_{1}\right)=d(A, B)=d\left(u_{2}, T x_{2}\right) \quad \Rightarrow \quad d\left(u_{1}, u_{2}\right) \leq \varphi\left(d\left(g x_{1}, g x_{2}\right)\right)
$$

for all $u_{1}, u_{2}, x_{1}, x_{2}$ in $A$. 
Now, we are ready to state our first main result in this section.

Theorem 3.1 Let $A$ and $B$ be nonempty closed subsets of a complete metric space $(X, d)$ such that $B$ is approximately compact with respect to $A$. Moreover, assume that $A_{0}$ and $B_{0}$ are nonempty. Let $T: A \rightarrow B$ and $g: A \rightarrow A$ satisfy the following conditions.

(a) $T$ is a $(\varphi, g)$-proximal contraction,

(b) $T\left(A_{0}\right) \subseteq B_{0}$,

(c) $g$ is a one-to-one continuous map such that $g^{-1}: g(A) \rightarrow A$ is uniformly continuous,

(d) $A_{0} \subseteq g\left(A_{0}\right)$.

Then there exists a unique element $x \in A$ such that $d(g x, T x)=d(A, B)$. Further, for any fixed element $x_{0} \in A_{0}$, the sequence $\left\{x_{n}\right\}$ defined by $d\left(g x_{n+1}, T x_{n}\right)=d(A, B)$ converges to $x$.

Proof Let $x_{0}$ be a fixed element in $A_{0}$. Since $T\left(A_{0}\right) \subseteq B_{0}$ and $A_{0} \subseteq g\left(A_{0}\right)$, then there exists an element $x_{1} \in A_{0}$ such that $d\left(g x_{1}, T x_{0}\right)=d(A, B)$. Proceeding in this manner, having chosen $x_{n} \in A_{0}$, we can find $x_{n+1} \in A_{0}$ satisfying

$$
d\left(g x_{n+1}, T x_{n}\right)=d(A, B) \quad \text { for each } n \in \mathbb{N} .
$$

Since $T$ is a $(\varphi, g)$-proximal contraction, then from (3.1) we have

$$
d\left(g x_{n+1}, g x_{n+2}\right) \leq \varphi\left(d\left(g x_{n}, g x_{n+1}\right)\right) \quad \text { for each } n \in \mathbb{N} .
$$

We shall show that $\left\{g x_{n}\right\}$ is a Cauchy sequence. Let $\delta_{n}=d\left(g x_{n}, g x_{n+1}\right)$. From (3.2) we get that the sequence $\left\{\delta_{n}\right\}$ is non-increasing (note that $\varphi(t) \leq t$ for all $t \geq 0$ ). Therefore, there is some $\delta \geq 0$ such that $\lim _{n \rightarrow \infty} \delta_{n}=\delta^{+}$. We show that $\delta=0$. Suppose, to the contrary, that $\delta>0$. Then from (3.2) we get

$$
\delta=\lim _{n \rightarrow \infty} \delta_{n+1} \leq \limsup _{n \rightarrow \infty} \varphi\left(\delta_{n}\right)<\delta
$$

a contradiction. Thus $\delta=0$, that is,

$$
\lim _{n \rightarrow \infty} \delta_{n}=0 .
$$

Suppose, to the contrary, that $\left\{g x_{n}\right\}$ is not a Cauchy sequence. Then there exists an $\epsilon>0$ and two subsequences of integers $\{l(k)\}$ and $\{m(k)\}, m(k)>l(k) \geq k$ with

$$
r_{k}=d\left(g x_{l(k)}, g x_{m(k)}\right) \geq \epsilon \quad \text { for } k \in\{1,2, \ldots\} .
$$

We may also assume

$$
d\left(g x_{l(k)}, g x_{m(k)-1}\right)<\epsilon \quad \text { for } k \in\{1,2, \ldots\},
$$

by choosing $m(k)$ to be the smallest number exceeding $l(k)$ for which (3.4) holds. From (3.4), (3.5) and by the triangle inequality,

$$
\epsilon \leq r_{k} \leq d\left(g x_{l(k)}, g x_{m(k)-1}\right)+d\left(g x_{m(k)-1}, g x_{m(k)}\right)<\epsilon+\delta_{m(k)-1} .
$$


Taking the limit as $k \rightarrow \infty$, we get (note that $\lim _{k \rightarrow \infty} \delta_{m(k)-1}=0$ )

$$
\lim _{k \rightarrow \infty} r_{k}=\epsilon^{+} .
$$

By the triangle inequality

$$
\begin{aligned}
r_{k} & =d\left(g x_{l(k)}, g x_{m(k)}\right) \\
& \leq d\left(g x_{l(k)}, g x_{l(k)+1}\right)+d\left(g x_{l(k)+1}, g x_{m(k)+1}\right)+d\left(g x_{m(k)+1}, g x_{m(k)}\right) \\
& =\delta_{l(k)}+\delta_{m(k)}+d\left(g x_{l(k)+1}, g x_{m(k)+1}\right) .
\end{aligned}
$$

From (3.2), we have

$$
d\left(g x_{l(k)+1}, g x_{m(k)+1}\right) \leq \varphi\left(d\left(g x_{l(k)}, g x_{m(k)}\right)\right)=\varphi\left(r_{k}\right) .
$$

Then from (3.7) and (3.8), we have

$$
r_{k} \leq \delta_{l(k)}+\delta_{m(k)}+\varphi\left(r_{k}\right) .
$$

Letting $k \rightarrow \infty$ and using (3.2) and (3.6), we get

$$
\epsilon \leq \limsup _{k \rightarrow \infty} \varphi\left(r_{k}\right)<\epsilon
$$

a contradiction. Therefore $\left\{g x_{n}\right\}$ is a Cauchy sequence. Since $g^{-1}$ is uniformly continuous and $\left\{g x_{n}\right\}$ is a Cauchy sequence, then we get that $\left\{x_{n}\right\}$ is also a Cauchy sequence. Since $X$ is complete and $A \subseteq X$ is closed, there exists $x \in A$ such that $\lim _{n \rightarrow \infty} x_{n}=x$. Further, it can be noted

$$
\begin{aligned}
d(g x, B) & \leq d\left(g x, T x_{n}\right) \\
& \leq d\left(g x, g x_{n+1}\right)+d\left(g x_{n+1}, T x_{n}\right) \\
& \leq d\left(g x, g x_{n+1}\right)+d(A, B) \leq d\left(g x, g x_{n+1}\right)+d(g x, B) .
\end{aligned}
$$

Since $g$ is continuous and $\lim _{n \rightarrow \infty} x_{n}=x$, then $\lim _{n \rightarrow \infty} g x_{n}=g x$. Therefore from the above, $d\left(g x, T x_{n}\right) \rightarrow d(g x, B)$ as $n \rightarrow \infty$. Since $B$ is approximatively compact with respect to $A$, it follows that the sequence $\left\{T x_{n}\right\}$ has a subsequence converging to some element $y \in B$. Thus $d(g x, y)=d(A, B)$ and hence $g x \in A_{0}$. Since $A_{0} \subseteq g\left(A_{0}\right), g x=g u$ for some $u \in A_{0}$. Therefore $x=u \in A_{0}$. Since $T A_{0} \subseteq B_{0}$, then

$$
d(z, T x)=d(A, B) \quad \text { for some } z \in A .
$$

From (3.1), (3.2) and (3.9), we have

$$
d\left(g x_{n+1}, z\right) \leq \varphi\left(d\left(g x, g x_{n+1}\right)\right) \leq d\left(g x, g x_{n+1}\right) .
$$

Therefore

$$
z=\lim _{n \rightarrow \infty} g x_{n+1}=g x
$$


Hence

$$
d(g x, T x)=d(z, T x)=d(A, B) .
$$

Suppose that there is another $x^{*}$ such that

$$
d\left(g x^{*}, T x^{*}\right)=d(A, B) .
$$

Then from (3.10) and (3.11) we get

$$
d\left(g x, g x^{*}\right) \leq \varphi\left(d\left(g x, g x^{*}\right)\right)
$$

which implies that $x=x^{*}$.

The following theorem, which is the main result of Sadiq Basha [18], is immediate.

Theorem 3.2 Let $A$ and $B$ be nonempty closed subsets of a complete metric space $(X, d)$ such that $B$ is approximately compact with respect to $A$. Moreover, assume that $A_{0}$ and $B_{0}$ are nonempty. Let $T: A \rightarrow B$ and $g: A \rightarrow A$ satisfy the following conditions.

(a) $T$ is a proximal contraction,

(b) $T\left(A_{0}\right) \subseteq B_{0}$,

(c) $g$ is an isometry,

(d) $A_{0} \subseteq g\left(A_{0}\right)$

Then there exists a unique element $x \in A$ such that $d(g x, T x)=d(A, B)$. Further, for any fixed element $x_{0} \in A_{0}$, the sequence $\left\{x_{n}\right\}$ defined by $d\left(g x_{n+1}, T x_{n}\right)=d(A, B)$ converges to $x$.

Now we illustrate our best proximity point theorem by the following example.

Example 3.1 Consider the complete metric space $X=[0,1] \times[0,1]$ with Euclidean metric Let $A:=\{(0, x): 0 \leq x \leq 1\}$ and $B=\{(1, y): 0 \leq y \leq 1\}$. Then $d(A, B)=1, A_{0}=A$ and $B_{0}=B$. Let $g: A \rightarrow A$ be defined as $g(0, x)=\left(0, \frac{2 x}{1+x}\right)$. Then $g$ is a one-to-one continuous map, $g^{-1}: A \rightarrow A$ is uniformly continuous and $g\left(A_{0}\right)=A_{0}$.

Let $T: A \rightarrow B$ be defined as $T(0, x)=\left(1, \frac{x}{4}\right)$. Let $\varphi(t)=\frac{t}{2}$ for each $t \geq 0$. Then it is easy to see that $T$ is $(\varphi, g)$-proximal contraction. So, all the hypotheses of Theorem 3.1 are satisfied. Further, it is easy to see that $(0,0)$ is the unique element satisfying the conclusion of Theorem 3.1. However, we cannot invoke the above mentioned Theorem 3.2 of Sadiq Basha to show the existence of a best proximity point because $g$ is not an isometry.

The following are immediate consequences of Theorem 3.1.

Theorem 3.3 Let $A$ and $B$ be nonempty closed subsets of a complete metric space $(X, d)$ such that $B$ is compact. Moreover, assume that $B_{0}$ is nonempty. Let $T: A \rightarrow B$ and $g: A \rightarrow A$ satisfy the following conditions.

(a) $T$ is a $(\varphi, g)$-proximal contraction,

(b) $T\left(A_{0}\right) \subseteq B_{0}$,

(c) $g$ is a one-to-one continuous map such that $g^{-1}: g(A) \rightarrow A$ is uniformly continuous,

(d) $A_{0} \subseteq g\left(A_{0}\right)$. 
Then there exists a unique element $x \in A$ such that $d(g x, T x)=d(A, B)$. Further, for any fixed element $x_{0} \in A_{0}$, the sequence $\left\{x_{n}\right\}$ defined by $d\left(g x_{n+1}, T x_{n}\right)=d(A, B)$ converges to $x$.

Theorem 3.4 Let $(X, d)$ be a complete metric space and let $T, g: X \rightarrow X$ satisfy the following conditions.

(a) $T$ is a $(\varphi, g)$-contraction,

(b) $g: X \rightarrow X$ is a one-to-one, onto continuous map such that $g^{-1}$ is uniformly continuous.

Then there exists a unique element $x \in X$ such that $g x=T x$, that is, $(T, g)$ has a coincidence point $x$. Further, for any fixed element $x_{0} \in X$, the sequence $\left\{x_{n}\right\}$ defined by $g x_{n+1}=T x_{n}$ converges to $x$.

Theorem 3.5 Let $(X, d)$ be a complete metric space and let $T: X \rightarrow X$ be a $\varphi$-contraction. Then $T$ has a unique fixed point $x \in X$. Further, for any fixed element $x_{0} \in X$, the sequence $\left\{x_{n}\right\}$ defined by $x_{n+1}=T x_{n}$ converges to $x$.

Competing interests

The authors declare that they have no competing interests.

\section{Authors' contributions}

All authors contributed equally and significantly in writing this article. All authors read and approved the final manuscript.

\section{Author details}

${ }^{1}$ Department of Pure Mathematics, University of Shahrekord, Shahrekord, 88186-34141, Iran. ${ }^{2}$ Department of Mathematics, King Abdulaziz University, P.O. Box 80203, Jeddah, 21589, Saudi Arabia. ${ }^{3}$ Department of Mathematics, GDCW, Bosan Road, Multan, Pakistan.

\section{Acknowledgements}

This work was supported by the University of Shahrekord. The first author would like to express thanks for this support. The first author was also partially supported by the Center of Excellence for Mathematics, University of Shahrekord, Iran. This article was funded by the Deanship of Scientific Research (DSR), King Abdulaziz University, Jeddah. The second author acknowledges with thanks DSR, KAU for financial support.

Received: 9 May 2013 Accepted: 3 June 2013 Published: 25 June 2013

\section{References}

1. Fan, K: Extensions of two fixed point theorems of F. E. Browder. Math. Z. 112, 234-240 (1969)

2. Reich, S: Approximate selections, best approximations, fixed points and invariant sets. J. Math. Anal. Appl. 62, 104-113 (1978)

3. Prolla, JB: Fixed point theorems for set valued mappings and existence of best approximations. Numer. Funct. Anal. Optim. 5, 449-455 (1982/1983)

4. Hussain, N, Khan, AR, Agarwal, RP: Krasnosel'skii and Ky Fan type fixed point theorems in ordered Banach spaces. J. Nonlinear Convex Anal. 11(3), 475-489 (2010)

5. Hussain, N, Khan, AR: Applications of the best approximation operator to $*$-nonexpansive maps in Hilbert spaces. Numer. Funct. Anal. Optim. 24(3-4), 327-338 (2003)

6. Takahashi, W: Fan's existence theorem for inequalities concerning convex functions and its applications. In: Ricceri, B, Simons, S (eds.) Minimax Theory and Applications, pp. 597-602. Kluwer Academic, Dordrecht (1998)

7. Amini-Harandi, A: Best proximity points theorems for cyclic strongly quasi-contraction mappings. J. Glob. Optim. (2012). doi:10.1007/s10898-012-9953-9

8. Karpagam, S, Agrawal, S: Best proximity point theorems for $p$-cyclic Meir-Keeler contractions. Fixed Point Theory Appl. 2009, Article ID 197308 (2009)

9. Sadiq Basha, S: Best proximity points: global optimal approximate solution. J. Glob. Optim. 49, $15-21$ (2011)

10. Eldred, AA, Veeramani, P: Existence and convergence of best proximity points. J. Math. Anal. Appl. 323, $1001-1006$ (2006)

11. Suzuki, T, Kikkawa, M, Vetro, C: The existence of best proximity points in metric spaces with the property UC. Nonlinear Anal. 71, 2918-2926 (2009)

12. Di Bari, C, Suzuki, T, Vetro, C: Best proximity points for cyclic Meir-Keeler contractions. Nonlinear Anal. 69, 3790-3794 (2008)

13. Abkar, A, Gabeleh, M: Best proximity points for cyclic mappings in ordered metric spaces. J. Optim. Theory Appl. 151, 418-424 (2011)

14. Al-Thagafi, MA, Shahzad, N: Convergence and existence results for best proximity points. Nonlinear Anal. 70, 3665-3671 (2009) 
15. Mongkolkeha, C, Kumam, P: Best proximity point theorems for generalized cyclic contractions in ordered metric spaces. J. Optim. Theory Appl. (2012). doi:10.1007/s10957-012-9991-y

16. Amini-Harandi, A: Best proximity points for proximal generalized contractions in metric spaces. Optim. Lett. (2013). doi:10.1007/s11590-012-0470-z

17. Amini-Harandi, A: Common best proximity points theorems in metric spaces. Optim. Lett. (2012) doi:10.1007/s11590-012-0600-7

18. Sadiq Basha, S: Best proximity points: optimal solutions. J. Optim. Theory Appl. 151, 210-216 (2011)

19. Abkar, A, Gabeleh, M: Best proximity points of non-self mappings. Top (2013). doi:10.1007/s11750-012-0255-7

20. Kim, WK, Kum, S, Lee, KH: On general best proximity pairs and equilibrium pairs in free abstract economies. Nonlinear Anal. 68(8), 2216-2227 (2008)

21. Kirk, WA, Reich, S, Veeramani, P: Proximinal retracts and best proximity pair theorems. Numer. Funct. Anal. Optim. 24 851-862 (2003)

22. Geraghty, G: On contractive mappings. Proc. Am. Math. Soc. 40, 604-608 (1973)

doi:10.1186/1687-1812-2013-164

Cite this article as: Amini-Harandi et al.: Best proximity point results for generalized contractions in metric spaces.

Fixed Point Theory and Applications 2013 2013:164.

\section{Submit your manuscript to a SpringerOpen ${ }^{\circ}$ journal and benefit from:}

- Convenient online submission

Rigorous peer review

- Immediate publication on acceptance

- Open access: articles freely available online

- High visibility within the field

- Retaining the copyright to your article 